\title{
Concentrations and source identification of organochlorine pesticides (OCPs) in soils from Wolong Natural Reserve
}

\author{
ZHENG XiaoYan $^{1,2}$, LIU XianDe ${ }^{2 \dagger}$, LIU WenJie ${ }^{2}$, JIANG GuiBin ${ }^{1}$ \& YANG RuiQiang ${ }^{1}$ \\ ${ }^{1}$ State Key Laboratory of Environmental Chemistry and Ecotoxicology, Research Center for Eco-Environmental Sciences, Chinese \\ Academy of Sciences, Beijing 100085, China; \\ ${ }^{2}$ Chinese Research Academy of Environmental Sciences, Beijing 100012, China
}

In order to understand the distribution profile, composition characteristics and sources of OCPs, soil samples collected from Wolong Natural Reserve (WNR) in spring and autumn in 2005 were analyzed using gas chromatography coupled with electron capture detector (GC-ECD). Results showed that all OCPs concentrations were in the range of $10^{-2} \mathrm{ng} / \mathrm{g}-10^{-1} \mathrm{ng} / \mathrm{g}$, representing the background level in those remote sites. Generally, their concentrations were slightly higher in spring than in autumn, which could be explained by OCPs: 1) may be released to soil from snow-melting water in spring; 2) partially evaporate into air from soil due to high temperature and intense radiation in summer and 3) can be relatively high degradation rate in summer. There were notable differences of OCPs seasonal variations between samples from alpine meadow and those from under-treeline. This phenomenon was related to physical-chemical properties of OCPs and vegetation coverage. For alpine meadow soils, levels of OCPs were increased with increasing altitudinal gradient, which was associated with enhanced scavenging efficiency of wet precipitation. Composition characteristics of OCPs in soils were similar to those of air samples, which was distinct from those of typical contaminated soils, indicating that OCPs in WNR soils were mainly from atmospheric transport.

OCPs, soil, seasonal variation, composition characteristics, source identification

Organochlorine pesticides (OCPs), such as hexachlorocyclohexane (HCHs), dichloro-diphenyl-trichloroethane (DDTs) and hexachlorobenzene (HCB), are grouped into persistent organic pollutants (POPs) that have been banned for two or three decades in many countries including China. However, they are ubiquitous in the environment as a consequence of high lipophilicity, bioaccumulation, resistance to degradation, and propensity to undergo long-range transport, and even they can be found in high latitude or high altitude remote areas, like polar regions ${ }^{[1-3]}$, Tibetan Plateau ${ }^{[4,5]}$ and high mountains ${ }^{[6]}$. The transport mechanism, called the global distillation effect, describes the processes that semivolatile compounds emitted from diffusive sources at low-mid latitudes were transported to the higher latitudinal or altitudinal sites by atmospheric or aquatic transfer. Ecosystems in clean areas may be threatened by this mechanism; therefore, more attention should be paid to investigations on POPs levels, transfer and composition characteristics, especially in the high mountains.

Soils play an important role in the global distribution and fate of POPs because they not only have a large retention capacity but also re-emit these old organic pollutants into air as secondary source ${ }^{[7,8]}$. Researchers have observed that soils from remote areas were contaminated by POPs ${ }^{[1,4,6,9]}$. Soil loads of POPs reflect its flux from

Received May 4, 2008; accepted November 25, 2008 doi: 10.1007/s11434-009-0033-6

'Corresponding author (email: liuxdlxd@hotmail.com)

Supported by the National Basic Research Program of China (Grant No. 2003CB415003) 
air to soils ${ }^{[7]}$, which depends on soil application as well as its physicochemical properties such as volatilization, degradation and leaching that are greatly affected by temperatures ${ }^{[10,11]}$

Wolong Natural Reserve (WNR) in mountain area of western Sichuan Province was studied as a representative location. Soil concentrations of HCHs, DDTs, and HCB were measured. The distribution profiles along the altitudinal transect, composition characteristics and atmospheric transport of OCPs as well as the influences of seasonal variations, site elevation and vegetations coverage were discussed.

\section{Experimental}

\subsection{Study area}

WNR, located in the west mountains of Sichuan Province and the east edge of the Tibetan Plateau $\left(\mathrm{E} 102^{\circ} 52^{\prime}-103^{\circ} 24^{\prime}, \mathrm{N} 30^{\circ} 45^{\prime}-31^{\circ} 25^{\prime}\right)$, is a national nature reserve and famous for an endangered species, giant panda. Gengda River and Pitiao River, the upper branches of Minjiang River, flow through the central area of WNR. The altitude of mountains to the southeast of Pitiao River is generally less than $4000 \mathrm{~m}$, whereas that to the northwest of this river is almost about 5000 m.

WNR is governed by Tibetan Plateau's climate regime. In the winter half year (from November to the next April), WNR is mainly controlled by the southern branch of the westerlies, while in the summer half year (from May to October), this region is under the influence of southeast monsoon. WNR is an ideal area for investigating the distribution, transport and composition characteristics variation of POPs due to its unique features in geography, ecology and topography.

\subsection{Sampling}

Considering that OCPs concentrations may vary along with the change of climatic feature, soils were collected in the middle of April, 2005 (the end of winter half year) and the middle of October, 2005 (the end of summer half year), respectively (Table 1). According to the situation of vegetation cover and land application, soil samples collected along an altitudinal gradient were classified into two groups: one from alpine meadow (above Beimuping site) and the other from under-treeline (below Dengsheng site).

In each sampling site, surface soils (upper $10 \mathrm{~cm}$ ) were sampled at 3 to 5 spots within a circular area with a diameter of $20 \mathrm{~m}$ and homogenized into a bulk one using a solvent-washed stainless steel scoop. The residual soils on the scoop were scraped by local soils before collecting the next sample. Soil samples were immediately wrapped in aluminum foils heated at $450{ }^{\circ} \mathrm{C}$ for $4 \mathrm{~h}$ in the laboratory, then packed into airtight polyethylene bags, delivered to the laboratory and kept frozen at $-20^{\circ} \mathrm{C}$ until analysis.

\subsection{Reagent and materials}

The extract solvents of $n$-hexane and dichloromethane were of pesticides residue grade (Tedia, USA). Florisil PR (100-200 mesh, Supelco Inc., USA) was activated in the oven at $170^{\circ} \mathrm{C}$ for $13 \mathrm{~h}$. Anhydrous sodium sulfate was of analytical grade and was baked at $450^{\circ} \mathrm{C}$ for $4 \mathrm{~h}$. The activated Florisil PR and anhydrous sodium sulfate were stored in a sealed desiccator.

Table 1 Descriptions of the sampling sites and organic carbon content in soil samples in 2005

\begin{tabular}{|c|c|c|c|c|c|c|}
\hline \multirow{2}{*}{ Site No. } & \multirow{2}{*}{ Name } & \multirow{2}{*}{$\begin{array}{l}\text { Altitude (m.a.s.I.)/annual } \\
\text { average temperature }\left({ }^{\circ} \mathrm{C}\right)\end{array}$} & \multirow{2}{*}{ Vegetation and land application } & \multirow{2}{*}{ Sample No. } & \multicolumn{2}{|c|}{$\operatorname{sOC}(\%)$} \\
\hline & & & & & Spring & Autumn \\
\hline 1 & Tangfang & $3940 /-1.4$ & alpine meadow & S01 & 4.9 & 4.6 \\
\hline 2 & $\begin{array}{l}95 \mathrm{~km} \text { site of } 303 \\
\text { provincial highway }\end{array}$ & $3619 / 1.4$ & alpine meadow & S02 & 9.3 & 12 \\
\hline \multirow[t]{2}{*}{3} & Beimuping & $3377 / 2.8$ & hardy scrub and alpine meadow & S03 & 10 & 11 \\
\hline & & & & S04 & 10 & 10 \\
\hline 4 & Dengsheng & $2828 / 6.1$ & fir & S05 & 6.5 & 7.1 \\
\hline 5 & Lvlvdian & $2636 / 7.3$ & $\begin{array}{l}\text { coniferous-broadleaved mixed forest and } \\
\text { agriculture }\end{array}$ & S06 & 7.7 & 5.5 \\
\hline 6 & Sandao Bridge & $2190 / 10.0$ & coniferous-broadleaved mixed forest & S07 & 3.0 & 2.8 \\
\hline 7 & Hetaoping & $1847 / 12.1$ & Larch, coniferous-broadleaved mixed forest & S08 & 5.4 & 9.6 \\
\hline 8 & Gengda Town & $1439 / 14.5$ & $\begin{array}{l}\text { indeciduous/deciduous broadleaved mixed } \\
\text { forest }\end{array}$ & S09 & 3.7 & \\
\hline 9 & Shuijiepai & $1242 / 15.7$ & $\begin{array}{l}\text { indeciduous/deciduous broadleaved mixed } \\
\text { forest }\end{array}$ & $\mathrm{S} 10$ & 11 & 7.0 \\
\hline
\end{tabular}


The OCPs standards of $\alpha-\mathrm{HCH}, \beta-\mathrm{HCH}, \gamma-\mathrm{HCH}$, $\delta$-HCH, HCB, $p, p^{\prime}$-DDE, $p, p^{\prime}$-DDD, $p, p^{\prime}$-DDT, $o, p^{\prime}-$ DDT and internal standard pentachloronitrobenzene (PCNB) were purchased from National Research Center for Certified Reference Materials of China. Two surrogate standards (2,4,5,6-tetrachloro-m-xylene, TMX and decachlorobiphenyl, PCB209) were purchased from J\&K Inc.

\subsection{Extraction and purification}

Samples were freeze-dried and pulverized to sieve at 40 mesh until becoming homogenous. A 5-g sample with activated copper powder, spiked with surrogate standards (10 ng TMX and 40 ng PCB209), was extracted

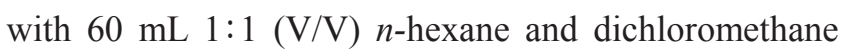
for $0.5 \mathrm{~h}$ using ultrasonic bath. The sample was stood overnight, then sonicated again for another $0.5 \mathrm{~h}$ and centrifuged. The extracts were reduced to $1-2 \mathrm{~mL}$ with rotary evaporator. The OCPs purification was conducted on a chromatography column (17 $\mathrm{mm}$ i.d), packed with $6 \mathrm{~g}$ florisil and $2 \mathrm{~cm}$ sodium sulfate from the bottom to top, which was conditioned with $50 \mathrm{~mL}$ 1:4 (V/V) $n$-hexane and dichloromethane. The elution was done with $70 \mathrm{~mL} 1: 4(\mathrm{~V} / \mathrm{V})$ dichloromethane and $n$-hexane. The eluates were concentrated to $200 \mu \mathrm{L}$ under a gentle stream of pure nitrogen, and $8 \mathrm{ng}$ PCNB was added as internal standard before GC analysis.

\subsection{Instrumental analysis}

The sample extracts were analyzed on an Agilent 6890 gas chromatography (GC) coupled with an electron capture detector (ECD). The separation was accomplished with an HP-5 fused silica capillary column (30 $\mathrm{m} \times 0.32 \mathrm{~mm}$ i.d. $\times 0.25 \mu \mathrm{m}$ film thickness). One $\mu \mathrm{L}$ sample extract was injected with splitless mode. The carrier gas was high purity nitrogen. The oven temperature program was as follows: $80^{\circ} \mathrm{C}$ for $1 \mathrm{~min}$, ramped at $10^{\circ} \mathrm{C} \mathrm{min}^{-1}$ to $180^{\circ} \mathrm{C}$, held for $5 \mathrm{~min}$, ramped at $2.0^{\circ} \mathrm{C}$ $\min ^{-1}$ to $200^{\circ} \mathrm{C}$, ramped at $1.0^{\circ} \mathrm{C} \mathrm{min}^{-1}$ to $215^{\circ} \mathrm{C}$, held for $4 \mathrm{~min}$, and finally ramped at $25.0^{\circ} \mathrm{C} \mathrm{min}^{-1}$ to $280^{\circ} \mathrm{C}$ and held for $5 \mathrm{~min}$. The temperatures of injector and detector were $250^{\circ} \mathrm{C}$ and $330^{\circ} \mathrm{C}$, respectively. Identification of OCPs was determined by retention time. A five-point calibration was carried out using an internal standard method.

\subsection{Quality control}

All solvents used have no interfering peaks according to $\mathrm{GC}$ analysis. A procedure blank and a sample duplicate were processed for every 8 samples. In the blank procedure, $\mathrm{HCB}, \alpha-\mathrm{HCH}$ and $\gamma-\mathrm{HCH}$ had been shown to be 3 times higher than signal/noise of GC; thereby, all data were blank-corrected. The relative standard derivation (RSD) values of OCPs, with five duplicated measurements, were less than $20 \%$. The recovery of surrogates was $76 \pm 6.6 \%$ for TMX and $98 \pm 7.1 \%$ for PCB209 respectively. A calibrated standard was measured to monitor GC performance after 10 injections. The degradation of $p, p^{\prime}$-DDT in injector was $<15 \%$ for daily check.

\section{Results and discussion}

\subsection{Concentrations of OCPs}

Table 2 shows the OCPs concentrations in soils at WNR and a comparison with other clean areas. It was shown that OCPs concentrations in WNR soils were generally low. In spring, the concentrations of $\mathrm{\Sigma HCHs}$ ranged

Table 2 Concentrations of OCPs found in the soils from WNR and comparison with other mountainous areas (ng/g)

\begin{tabular}{|c|c|c|c|c|c|}
\hline & \multicolumn{2}{|c|}{${\text { This } \text { work }^{\text {a) }}}$} & \multicolumn{3}{|c|}{ Soils from other clean areas } \\
\hline & Spring & Autumn & Tibet $^{[4]}$ & Teide, Spain ${ }^{[12]}$ & Antarctic area $^{[1]}$ \\
\hline$\alpha-\mathrm{HCH}$ & $0.20(0.015-0.47)$ & $0.084(0.063-0.53)$ & $0.10-2.55$ & $0.059 \pm 0.12$ & $0.09-3.9$ \\
\hline$\beta-\mathrm{HCH}$ & $0.042(0.014-0.65)$ & $0.041(0.025-0.14)$ & $\mathrm{nd}-1.29$ & - & $0.03-0.32$ \\
\hline$\gamma-\mathrm{HCH}$ & $0.58(0.089-1.04)$ & $0.24(0.11-0.33)$ & $0.05-1.77$ & $0.049 \pm 0.1$ & $0.71-55$ \\
\hline$\delta \mathrm{HCH}$ & $0.034(0.009-0.11)$ & $0.028(n d-0.033)$ & $\mathrm{nd}-0.03$ & $0.0015 \pm 0.0029$ & $0.00-0.57$ \\
\hline$\Sigma \mathrm{HCHs}$ & $0.64(0.15-1.35)$ & $0.40(0.23-0.80)$ & $0.18-5.38$ & - & $0.86-59.7$ \\
\hline$p, p^{\prime}-\mathrm{DDE}$ & $0.17(0.058-1.04)$ & $0.18(0.096-0.24)$ & $0.00-2.83$ & $3.4 \pm 7.9$ & $0.03-3.19$ \\
\hline$p, p^{\prime}-\mathrm{DDD}$ & $\mathrm{nd}(\mathrm{nd}-0.15)$ & $0.007(\mathrm{nd}-0.022)$ & $\mathrm{nd}-0.36$ & - & $0.03-3.1$ \\
\hline$o, p^{\prime}-\mathrm{DDT}$ & $0.11(n d-0.45)$ & $0.088(0.055-0.15)$ & $\mathrm{nd}-0.34$ & - & $0.00-6.27$ \\
\hline$p, p^{\prime}$-DDT & $0.23(0.15-1.81)$ & $0.19(\mathrm{nd}-0.29)$ & $\mathrm{nd}-0.52$ & $2.0 \pm 4.3$ & $0.04-15$ \\
\hline ¿DDTs & $0.64(0.34-3.15)$ & $0.37(0.21-0.66)$ & $\mathrm{nd}-2.83$ & $5.4(0.01-40)^{*}$ & $0.1-25.6$ \\
\hline HCB & $0.083(0.02-0.20)$ & $0.13(0.054-0.64)$ & - & $0.31 \pm 0.55$ & $0.02-25$ \\
\hline
\end{tabular}

a) The median value with range in parenthesis; nd: not detected; *: The mean of sum of $p, p^{\prime}-\mathrm{DDE}$ and $p, p^{\prime}$-DDT in ref. [12]. 
from $0.15 \mathrm{ng} / \mathrm{g}$ to $1.35 \mathrm{ng} / \mathrm{g}$ (median, $0.64 \mathrm{ng} / \mathrm{g}$ ). These values were comparable to those reported in Tibet and lower than those in Antarctic, but slightly higher than those in Teide clean mountain area, Tenerife, Spain. $\Sigma$ DDTs were between $0.34 \mathrm{ng} / \mathrm{g}$ and $3.15 \mathrm{ng} / \mathrm{g}$ (median, $0.64 \mathrm{ng} / \mathrm{g}$ ), which were similar to those in soils from Tibet and mostly lower than the concentrations reported from Antarctic and Teide mountain area. HCB, 0.02$0.20 \mathrm{ng} / \mathrm{g}$ (median, $0.083 \mathrm{ng} / \mathrm{g}$ ), was consistent with the concentrations detected in soils from Antarctic and Teide mountain area and close to the global background value of $0.68 \mathrm{ng} / \mathrm{g}^{[13]}$. OCPs concentrations in autumn soil were lower than those in spring soil. The results indicated that WNR is a pristine region.

\subsection{Seasonal variations of OCPs}

Soil organic matter (SOC) is generally regarded as a preferential medium for the sorption of hydrophobic pollutants. In order to elucidate the adsorption of OCPs by soil, the contents of SOC were measured (Table 1). Then the OCPs concentrations were normalized to SOC (Tables 3 and 4).

HCHs: Concentrations of $\mathrm{HCHs}$ were low in most spring soils, indicating that WNR is a pristine area. However, an exceptional high concentration was found at Sandaoqiao site (S07), possibly resulting from the local contamination. The altitudinal variations of $\mathrm{HCHs}$ in autumn were in agreement with those in spring. The concentration of HCHs in S07 was again the highest in autumn, which further confirmed the existence of local contamination. The percentages of $\beta-\mathrm{HCH}$ to $\Sigma \mathrm{HCHs}$ in S07 were $55 \%$ in spring and $36 \%$ in autumn, respectively, much higher than the other sites. High level of $\mathrm{HCHs}$ in $\mathrm{S} 07$ was caused by relatively abnormal value of $\beta$ - $\mathrm{HCH}$.

DDTs: DDTs concentrations, especially $p, p^{\prime}$-DDT in spring soils from under-treeline sites, were higher than those from alpine meadow sites (Table 3). In contrast with the other three chemicals, the concentrations of $p, p^{\prime}$-DDT were much higher. While in autumn soils, concentration variations of DDTs along the altitudinal gradient were not significant. The percentage of $p, p^{\prime}$-DDE approached to $p, p^{\prime}$-DDT which was still predominant among DDTs (Table 4).

HCB: Concentrations of HCB in spring and autumn soils were similar (Tables 3 and 4 ). It is known that HCB is extremely persistent in the environment. Among OCPs mentioned above, HCB is the most volatile with strong persistence, low water solubility and a long half-life (about 80 days or even much longer) in air. Therefore, it is prone to disperse thoroughly and undergo long-range atmospheric transport ${ }^{[13]}$. The atmospheric transport is an efficient way for the POPs to redistribute from contaminated lands to pristine soils, resulting in homogenous contents of POPs on a large scale in remote area. In this study, concentrations of HCB based on dry weight in WNR soils were at the level of global background value, so it could be inferred that HCB in WNR soils was mainly from atmospheric transport.

Table 3 Soil organic carbon-normalized concentrations of OCPs in soils from WNR, in spring in 2005 (ng/g (SOC))

\begin{tabular}{|c|c|c|c|c|c|c|c|c|c|c|c|}
\hline \multirow{2}{*}{ Sample } & \multicolumn{5}{|c|}{$\mathrm{HCHs}$} & \multicolumn{5}{|c|}{ DDTs } & \multirow{2}{*}{$\mathrm{HCB}$} \\
\hline & $\alpha-\mathrm{HCH}$ & $\beta-\mathrm{HCH}$ & $\gamma-\mathrm{HCH}$ & $\delta-\mathrm{HCH}$ & $\Sigma \mathrm{HCHs}$ & $p, p^{\prime}-\mathrm{DDE}$ & $p, p^{\prime}$-DDD & $o, p^{\prime}$-DDT & $p, p^{\prime}$-DDT & ¿DDTs & \\
\hline S01 & 3.6 & 1.2 & 21 & 1.6 & 28 & 3.1 & ND & 1.4 & 3.4 & 7.9 & 3.7 \\
\hline S02 & 1.6 & 0.35 & 4.6 & 0.36 & 6.9 & 1.7 & ND & 1.2 & 2.3 & 5.2 & 1.9 \\
\hline S03 & 2.3 & 0.22 & 1.5 & 0.095 & 4.1 & 1.2 & ND & 0.46 & 1.9 & 3.6 & 0.71 \\
\hline S04 & 2.7 & 0.24 & 2.9 & 0.13 & 6.0 & 1.0 & ND & 0.77 & 1.5 & 3.3 & 1.1 \\
\hline avg. & 2.5 & 0.49 & 7.6 & 0.55 & 11 & 1.8 & & 0.96 & 2.3 & 5.0 & 1.9 \\
\hline S05 & 1.4 & 0.65 & 5.0 & 0.31 & 7.3 & 4.1 & ND & 2.3 & 3.5 & 9.9 & 3.1 \\
\hline S06 & 3.9 & 0.18 & 1.3 & 0.23 & 5.6 & 0.75 & ND & 0.54 & ND & 1.3 & 0.52 \\
\hline S07 & 6.5 & 21 & 7.1 & 3.8 & 39 & 5.6 & ND & ND & 5.8 & 11 & 0.59 \\
\hline S08 & 7.8 & 1.9 & 8.1 & 0.66 & 18 & 3.9 & 0.33 & 3.9 & 6.2 & 14 & 1.5 \\
\hline $\mathrm{S} 08^{\prime a)}$ & 8.7 & 1.8 & 8.9 & 0.85 & 20 & 3.8 & 0.36 & 4.1 & 6.9 & 15 & 1.5 \\
\hline S09 & 0.40 & 0.94 & 2.4 & 0.24 & 4.0 & 5.4 & 0.49 & 6.2 & 7.5 & 20 & 1.1 \\
\hline S10 & 1.6 & 3.0 & 2.7 & 0.41 & 7.6 & 9.2 & 1.3 & 4.0 & 13 & 28 & 1.5 \\
\hline RSD\% & 78 & 179 & 60 & 138 & 85 & 55 & 77 & 54 & 46 & 58 & 61 \\
\hline
\end{tabular}

a) the duplicate of $\mathrm{S} 08$. 
Comparison of seasonal variations: The percentage of the mean concentration difference (PMCD) of OCPs in soils between spring and autumn is presented in Table 5. The results showed that for alpine meadow soils, PMCD of HCHs was higher than that of DDTs ( $\Sigma \mathrm{HCHs}$ $>\Sigma$ DDTs), and PMCD of HCB was similar to that of $\Sigma$ DDTs. For under-treeline soils, PMCDs of $\Sigma \mathrm{HCH}$ and $\Sigma$ DDTs were similar to each other while HCB was close to zero. Compared with the physicochemical properties of these three kinds of OCPs, the $\log K_{\mathrm{AW}}$ of $\mathrm{HCHs}$ is lower than DDTs and much lower than HCB, indicating that $\mathrm{HCHs}$ could be deposited more readily into terrestrial surface through wet precipitation. Similarly, Log$K_{\mathrm{OW}}$ of $\mathrm{HCHs}$ is also smaller compared with those of DDTs and HCB, which means that HCHs are less retainable by organic-matter-rich compartments. Moreover, water solubility of $\mathrm{HCHs}$ is larger than the other two kinds of OCPs. Therefore, when these three kinds of
OCPs release into terrestrial compartments, $\mathrm{HCHs}$ are most unlikely to be retained and therefore, behave more actively relative to DDTs and HCB.

The dominant precipitation in WNR is often in the form of snow in winter half year and in the form of rain in summer half year. In winter cold season, organic contaminants in air can be effectively scavenged by snow. Specially, HCHs could be scavenged more efficiently than DDTs and HCB due to their physicochemical properties. Compared with rain, snow has a longer time to remain on the surface of land, thereby providing more opportunities for organic chemicals scavenged to be delivered into land surface with the snowmelt water. Therefore, the process of snowmelt in spring has a larger contribution for transferring $\mathrm{HCHs}$ to soil than that of DDTs and HCB. By contrast, in summer, the organic chemicals scavenged by abundant rain had less time to interact with soils because residence time of rain on the

Table 4 Soil organic carbon-normalized concentrations of OCPs in soils from WNR, in autumn in 2005 (ng/g (SOC))

\begin{tabular}{|c|c|c|c|c|c|c|c|c|c|c|c|}
\hline \multirow{2}{*}{ Sample } & \multicolumn{5}{|c|}{$\mathrm{HCHs}$} & \multicolumn{5}{|c|}{ DDTs } & \multirow{2}{*}{ HCB } \\
\hline & $\alpha-\mathrm{HCH}$ & $\beta-\mathrm{HCH}$ & $\gamma-\mathrm{HCH}$ & $\delta \mathrm{HCH}$ & $\Sigma \mathrm{HCHs}$ & $p, p^{\prime}$-DDE & $p, p^{\prime}-\mathrm{DDD}$ & $o, p^{\prime}$-DDT & $p, p^{\prime}$-DDT & ¿DDTs & \\
\hline S01 & 1.4 & 1.2 & 5.3 & 0.63 & 8.4 & 2.1 & 0.24 & 1.2 & 1.1 & 4.6 & 1.9 \\
\hline S02 & 1.7 & 0.35 & 1.2 & 0.28 & 3.5 & 1.8 & 0.10 & 1.3 & 2.5 & 5.7 & 2.2 \\
\hline S03 & 1.5 & 0.23 & 0.95 & 0.13 & 2.8 & 1.5 & 0.06 & 0.97 & 2.6 & 5.2 & 1.5 \\
\hline S04 & 5.2 & 0.25 & 2.5 & ND & 7.9 & 1.8 & ND & 0.95 & 2.5 & 5.2 & 2.1 \\
\hline avg. & 2.4 & 0.50 & 2.5 & 0.35 & 5.7 & 1.8 & 0.13 & 1.1 & 2.2 & 5.2 & 1.9 \\
\hline RSD\% & 76 & 91 & 79 & 75 & 51 & 13 & 72 & 15 & 34 & 8.4 & 16 \\
\hline S05 & 1.1 & 0.38 & 1.5 & 0.20 & 3.2 & 2.4 & ND & 0.83 & 1.4 & 4.6 & 9.0 \\
\hline S06 & 1.6 & 0.69 & 6.0 & 0.54 & 8.8 & 2.4 & 0.39 & 1.5 & 3.4 & 7.6 & 1.1 \\
\hline S07 & 2.3 & 5.1 & 5.9 & 1.0 & 14 & 7.3 & 0.78 & 2.4 & 5.6 & 16 & 1.9 \\
\hline S08 & 0.88 & 0.49 & 2.5 & 0.17 & 4.1 & 1.9 & ND & 1.1 & 1.5 & 4.5 & 0.73 \\
\hline S10 & 1.2 & 0.65 & 4.5 & 0.23 & 6.5 & 3.5 & ND & 1.3 & ND & 4.7 & 1.9 \\
\hline avg. & 1.4 & 1.5 & 4.1 & 0.43 & 7.4 & 3.5 & 0.58 & 1.4 & 3.0 & 7.5 & 2.9 \\
\hline RSD\% & 39 & 139 & 49 & 83 & 60 & 64 & 46 & 42 & 67 & 66 & 116 \\
\hline
\end{tabular}

ND: not detected.

Table 5 Difference of average concentration (normalized with SOC content) between spring and autumn for alpine meadow and under-treeline soils, respectively*

\begin{tabular}{|c|c|c|c|c|c|c|}
\hline & $\log K_{\mathrm{AW}}$ & $\mathrm{C}_{\mathrm{L}}\left(\mathrm{mol} / \mathrm{m}^{3}\right)$ & $\log K_{\text {ow }}$ & $\log K_{\mathrm{OA}}$ & Soils from alpine meadow $\Delta \%$ & Soils from under-treeline $\Delta \%$ \\
\hline$\alpha-\mathrm{HCH}$ & -3.53 & 0.333 & 3.94 & 7.46 & 4.6 & 70 \\
\hline$\beta-\mathrm{HCH}$ & -4.83 & 1.44 & 3.91 & 8.74 & -2.4 & 61 \\
\hline$\gamma-\mathrm{HCH}$ & -3.91 & 0.247 & 3.83 & 7.74 & 67 & 23 \\
\hline$\delta \mathrm{HCH}$ & & & & & 37 & 37 \\
\hline$\Sigma \mathrm{HCHs}$ & & & & & 49 & 46 \\
\hline$p, p^{\prime}-\mathrm{DDE}$ & -2.77 & 0.00079 & 4.2 & 9.70 & -1.3 & 26 \\
\hline$p, p^{\prime}-\mathrm{DDD}$ & -3.7 & 0.0023 & 6.33 & 10.03 & & 7.5 \\
\hline$o, p^{\prime}-\mathrm{DDT}$ & & & & & -15 & 60 \\
\hline$p, p^{\prime}-\mathrm{DDT}$ & -3.34 & 0.00042 & 6.39 & 9.73 & 5.0 & 59 \\
\hline$\Sigma \mathrm{DDT} \mathrm{s}$ & & & & & -3.1 & 47 \\
\hline $\mathrm{HCB}$ & -1.57 & 0.0014 & 5.64 & 7.21 & -3.4 & -0.9 \\
\hline
\end{tabular}

*: $\mathrm{D} \%=\left(\right.$ spring mean concentration-autumn mean concentration)/spring's ${ }^{*} 100$. Calculation of $\mathrm{HCHs}$ did not include S07 value for contaminated site. In calculation of $\mathrm{HCB}, \mathrm{S} 05$ was excluded. Physical-chemical properties were adjusted at $25^{\circ} \mathrm{C}^{[14,15]}$. 
land surface was relatively short. Furthermore, because of the higher water solubility, $\mathrm{HCHs}$ were easier to dissolve and be washed out with surface runoff than the others. All these factors described above may lead to the most significant seasonal variation of $\mathrm{HCHs}$ concentration in soil. Meanwhile, alpine meadow area is far away from anthropogenic activities and has sparse vegetation cover and low capacity of soil to retain the chemicals. Higher HCHs PMCD in this area could be attributed to these factors.

Under-treeline samplings were close to human living area. The sampling sites were characterized by dense vegetation cover and organic-rich soil, which favored uptake of organic chemicals. Because $\log K_{\mathrm{OA}}$ and $\log$ $K_{\mathrm{OW}}$ of DDTs are higher than those of HCHs, DDTs could be more readily adsorbed by the lipid-rich media like vegetation. Table 1 shows that the under-treeline vegetation was mostly composed of indeciduous and deciduous broadleaved mixed forest. During leaf development in spring, the coverage of vegetation extends significantly. The filter and uptake effects of vegetation reduce the organic chemical concentration in air and aquatic system. DDTs with higher lipophilic were prone to be adsorbed by the plant cuticle ${ }^{[16]}$ compared with HCHs and HCB. When sampling in autumn (October), the plants did not defoliate, and foliar uptake of DDTs did less transport from the canopy to soils. However, these DDTs could enter into surface media with a litter fall in late autumn, through long decay over winter, and finally enhanced the spring soil concentration. Therefore, PMCD (47\%) of DDTs was clearly observed for under-treeline sites, while PMCD of DDTs was rather small $(-3.1 \%)$ for alpine meadow sites. The vegetation filter and uptake effects on lower lipophilic $\mathrm{HCHs}$ were relatively weak ${ }^{[16]}$ and consequently, the PMCD was similar for both alpine meadow and under-treeline sites. Additionally, the vegetation filter and uptake effects retained more organic chemicals in the terrestrial environment especially in forest soils ${ }^{[16]}$. Vegetation and cloud cover also reduced direct solar radiation, thus resulting in a relatively small rate of photolytic degradation, which may lead to the fact that mostly OCPs concentrations were slightly higher in under-treeline soils than alpine meadow soils. HCB was distributed evenly ${ }^{[13]}$ and showed small seasonal variations due to the relatively strong volatilization $\left(\log K_{\mathrm{AW}}=-1.57\right)$, which brought about small PMCD approaching to zero.
It was intriguing that seasonal concentration variations of most OCPs, higher in spring than autumn, were consistent with the result obtained by simulating the influence of snow on the fate of $\alpha-\mathrm{HCH}^{[17]}$. WNR has high altitude and long wintertime with frequently dry and wet precipitation like snow and/or haze. The deposition of $\alpha-\mathrm{HCH}$ was continuously accumulated in snowpack from November to the following April when snow cover existed. While the deposited $\alpha-\mathrm{HCH}$ will be partially released to terrestrial compartments with snowmelt (including melt water and the particle flush), which leads to rising concentration in soil in spring. At high temperature and under intense microbes activity during summer, the re-evaporation and microbial degradation of $\alpha-\mathrm{HCH}$ were enhanced, as well as plentiful rainfall impelling the loss of $\alpha-\mathrm{HCH}$, which resulted in slightly low soil concentration in autumn. The causes of other OCPs seasonal variations were similar to $\alpha-\mathrm{HCH}$.

\subsection{Mountain cold condensation of OCPs}

For alpine meadow soils, the concentrations of $\Sigma \mathrm{HCHs}$, $\Sigma$ DDTs and HCB increased with increasing altitudinal gradient along the mountain slope, showing "cold condensation". Previous research ${ }^{[18]}$ pointed out that there are two preconditions for "cold condensation": the first is that all samples should be collected along the same mountain slope so that the sampling sites bear similar "emission sources-receptor" relationship. The other is free of local pollution sources. The alpine meadow sites in WNR satisfy these two preconditions.

The distribution profiles of OCPs in air were fairly uniform along the WNR altitudinal gradient. Due to the ascending height, decreasing temperature and the change of precipitation form, semivolatile organic compounds could partition into condensed phase (such as rain, snow and aerosol) with enhanced efficiency of precipitation scavenging ${ }^{[19]}$. Thus the enhanced deposition of OCPs to soil, vegetation and water would occur at the higher elevation, which led to the increasing trends of OCP levels. In this work, OCPs in alpine meadow soils displayed "cold condensation effect" (Table 3). However, the number of soil samples was limited in this work. Further studies are needed ${ }^{[20,21]}$.

\subsection{Source identification of OCPs}

In order to identify the possible sources of OCPs in WNR, isomer ratios of $\mathrm{HCHs}$ and ratio of member 

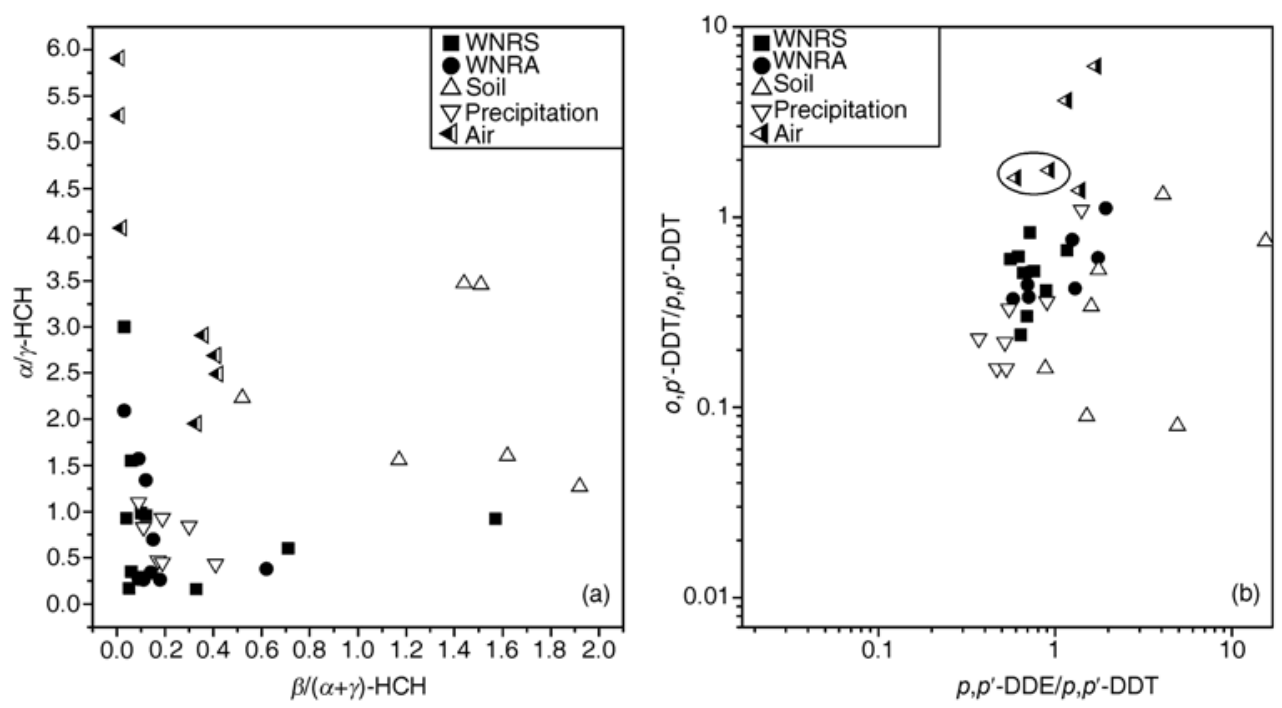

Figure 1 Comparison of the isomer ratios of OCPs in WNR soils with those in previous studies. WNRS: Spring soils at WNR; WNRA: Autumn soils at WNR. For convenient comparison, abscissa and ordinate of (b) refers to log-transformed axis.

compounds of DDTs in WNR soils were compared with those of contaminated soils ${ }^{[4,22-26]}$ and air-related samples $^{[27-33]}$ (e.g., precipitation and air samples) in previous studies (Figure 1).

For $\mathrm{HCHs}, \alpha-\gamma-\mathrm{HCH}$ was used as ordinate while $\beta-/(\alpha+\gamma)-\mathrm{HCH}$ as the abscissa (Figure 1(a)). The $\alpha-/ \gamma-\mathrm{HCH}$ ratio in the technical $\mathrm{HCH}$ is around $3.6-15$, while $\alpha-\gamma-\mathrm{HCH}$ ratio in lindane is less than 0.1 . Therefore, $\alpha-/ \gamma-\mathrm{HCH}$ ratio was often used to distinguish the potential sources and long-range atmospheric transport of HCHs. The vapor pressures of $\alpha-\mathrm{HCH}$ and $\gamma-\mathrm{HCH}$ are larger than $\beta$ - $\mathrm{HCH}$ (Table 5), indicating that the former more easily exists in gas phase, while $\beta$-HCH is most stable and persistent among all $\mathrm{HCH}$ isomers due to symmetric chemical structure. Therefore, $\beta$ - $\mathrm{HCH}$ will be the predominant isomers in soils with time elapse, and the proportion of $\beta-\mathrm{HCH}$ to the total $\mathrm{HCHs}$ is comparatively high in contaminated soil ${ }^{[34]}$, suggesting that $\beta-/(\alpha+\gamma)-\mathrm{HCH}$ can be used to differentiate whether $\mathrm{HCHs}$ are from aged contamination or not. By comparing the two kinds of ratios of this study with data from literature, the major sources of $\mathrm{HCHs}$ in WNR soils may be identified.

As shown in Figure 1(a), most ratios of $\mathrm{HCHs}$ in WNR soils were similar to air-related samples with $\beta-/(\alpha+\gamma)-\mathrm{HCH}$ less than 0.5. And thus it could be inferred that HCHs in WNR soils were from atmospheric deposition. The $\beta-/(\alpha+\gamma)-\mathrm{HCH}$ ratios of $\mathrm{S} 07$ and $\mathrm{S} 10$ were lager than 0.5 , reflecting the characteristics of con- taminated soils. S07 may be locally contaminated. Although low concentrations of $\mathrm{HCHs}$ were found in S10, the possibility of historical usage of this chemical can not be excluded in view of the relative low altitude and dense human activities at the site.

In general, $p, p^{\prime}$-DDT will be degraded to $p, p^{\prime}$-DDE under aerobic conditions whereas $p, p^{\prime}$-DDD under anaerobic conditions. $p, p^{\prime}$-DDE in the environment is mostly from the metabolite of $p, p^{\prime}$-DDT. Therefore, the ratio of $p, p^{\prime}$-DDE $/ p, p^{\prime}$-DDT could be used as a proxy to reveal the history period of DDTs released to the environment. Namely, low ratio of $p, p^{\prime}-\mathrm{DDE} / p, p^{\prime}$-DDT indicates the recent usage of DDTs, and the ratio of $o, p^{\prime} \mathrm{DDT} / p, p^{\prime}$-DDT could show whether there was usage of dicofol. Technical DDT includes less than $15 \%$ of $o, p^{\prime}$-DDT and higher than $85 \%$ of $p, p^{\prime}$-DDT, and the ratio of $o, p^{\prime}$-DDT $/ p, p^{\prime}$-DDT was about 0.175 . Although technical DDT was banned for agricultural purpose in China from 1983, dicofol as nonsystemic acaricide is still extensively used for the control of mites. In the technical dicofol, there are considerable impurities of DDTs in which the $o, p^{\prime}$-DDT is the predominant species and the ratio of $o, p^{\prime}$-DDT/ $p, p^{\prime}$-DDT is about $7^{[35]}$.

Figure 1(b) shows that DDTs-related ratios in WNR soils in spring and autumn was also similar to air-related samples (including two air samples from WNR that are signed with a ellipse in Figure 1(b)), but was significantly different from the typical contaminated soils, implying that DDTs in WNR soils were from atmospheric deposition. $p, p^{\prime}$-DDE/ $p, p^{\prime}$-DDT ratios in WNR soils ap- 
proached to 1 (Figure 1(b)), suggesting the possible occurrence of fresh input of DDT in this area. The ratio of $o, p^{\prime}$-DDT $/ p, p^{\prime}$-DDT was obviously larger than 0.175 . As their half-life time for phytodegradation is similar ${ }^{[31]}$, the high ratio of $o, p^{\prime}$-DDT $/ p, p^{\prime}$-DDT in WNR air (larger than 1 (Figure 1), indicates fresh input of dicofol. Similar observations were reported for central-Himalayas spruce needles ${ }^{[5]}$.

\section{Summary}

The concentrations of OCPs in WNR soils are relative low, which are comparable to those in typical pristine region such as Arctic, Antarctic and Tibetan Plateau. The low concentration of WNR implies this area is a suitable area to study long range atmospheric transport of POPs. Especially, alpine meadow sites were found to have no

1 Negoita T G, Covaci A, Gheorghe A, et al. Distribution of polychlorinated biphenyls (PCBs) and organochlorine pesticides in soils from the East Antarctic coast. J Environ Monit, 2003, 5(2): 281-286

2 Yao Z W, Jiang G B, Cai Y Q, et al. Status of persistent organic pollutants and heavy metals in surface water of Arctic region. Chin Sci Bull, 2003, 2003, 48(2): 131-135

3 Zhang H S, Wang Z P, Lu B, et al. Occurrence of organochlorine pollutants in the eggs and dropping-amended soil of Antarctic large animals and its ecological significance. Sci China Ser D-Earth Sci, 2007, 50(7): 1086-1096

4 Fu S, Chu S, Xu X. Organochlorine pesticide residue in soils from Tibet, China. Bull Environ Contam Toxicol, 2001, 66(2): 171-177

5 Wang X P, Yao T D, Cong Z Y, et al. Gradient distribution of persistent organic contaminants along northern slope of central-Himalayas, China. Sci Total Environ, 2006, 372(1): 193-202

6 Barra R, Popp P, Quiroz R, et al. Persistent toxic substances in soils and waters along an altitudinal gradient in the Laja River Basin, Central Southern Chile. Chemosphere, 2005, 58(7): 905-915

7 Harner T, Bidleman T F, Jantunen L M M, et al. Soil-air exchange model of persistent pesticides in the United States cotton belt. Environ Toxicol Chem, 2001, 20(7): 1612-1621

8 Wild S R, Jones K C. Polynuclear aromatic hydrocarbons in the United Kingdom environment: a preliminary source inventory and budget. Environl Pollut, 1995, 88(1): 91-108

9 Meijer S N, Steinnes E, Ockenden W A, et al. Influence of environmental variables on the spatial distribution of PCBs in Norwegian and UK soils: implications for global cycling. Environ Sci Technol, 2002, 36(10): 2146-2153

10 Hippelein M, McLachlan M S. Soil/air partitioning of semivolatile organic compounds 2. Influence of temperature and relative humidity. Environ Sci Technol, 2000, 34(16): 3521-3526 local contamination, fulfilling the preconditions of random sampling.

The environmental processes influencing the concentrations, distribution and seasonal variations of OCPs mainly include precipitation (particularly, snow scavenging in winter), snowmelt flush in spring, enhanced evaporation by high temperature and intense radiation in summer, vegetation filter and uptake of organic compounds during leaf development and microbial degradation.

Both composition characteristics of OCPs and "cold condensation" in alpine area demonstrated that OCPs in WNR soil were mainly from atmospheric transport. Soil, as major reservoir and secondary source, may play an important role in the global cycles of OCPs.

The authors thank Prof. Frank Wania for the helpful discussion and the two reviewers for their constructive comments.

11 Sinkkonen S, Paasivirta J. Degradation half-life times of PCDDs, PCDFs and PCBs for environmental fate modeling. Chemosphere, 2000, 40(9-11): 943-949

12 Ribes A, Grimalt J O, Garcia C J T, et al. Temperature and organic matter dependence of the distribution of organochlorine compounds in mountain soils from the subtropical Atlantic (Teide, Tenerife Island). Environ Sci Technol, 2002, 36(9): 1879-1885

13 Barber J L, Sweetman A J, van Wijk D, et al. Hexachlorobenzene in the global environment: Emissions, levels, distribution, trends and processes. Sci Total Environ, 2005, 349(1-3): 1-44

14 Shen L, Wania F. Compilation, evaluation, and selection of physicalchemical property data for organochlorine pesticides. J Chem Eng Data, 2005, 50(3): 742-768

15 Xiao H, Li N Q, Wania F. Compilation, evaluation, and selection of physical-chemical property data for alpha-, beta-, and gammahexachlorocyclohexane. J Chem Eng Data, 2004, 49(2): 173-185

16 Wania F, McLachlan M S. Estimating the influence of forests on the overall fate of semivolatile organic compounds using a multimedia fate model. Environ Sci Technol, 2001, 35(3): 582-590

17 Daly G L, Wania F. Simulating the influence of snow on the fate of organic compounds. Environ Sci Technol, 2004, 38(15): 4176-4186

18 Daly G L, Wania F. Organic contaminants in mountains. Environ Sci Technol, 2005, 39(2): 385-398

19 Wania F. On the origin of elevated levels of persistent chemicals in the environment. Environ Sci Pollut Res, 1999, 6(1): 11-19

20 Chen D Z, Liu W J, Liu X D, et al. Cold-Trapping of Persistent Organic Pollutantsin the Mountain Soils of Western Sichuan, China, Environ Sci Technol, 2008, 42(24): 9086-9091

21 Wania F, Westgate J N. On the Mechanism of Mountain Cold-Trapping of Organic Chemicals. Environ Sci Technol, 2008, 42(24): $9092-9098$ 
22 Tao S, Xu F L, Wang X J, et al. Organochlorine pesticides in agricultural soil and vegetables from Tianjin. China. Environ Sci Technol, 2005, 39(8): 2494-2499

23 An Q, Dong Y H, Wang H, et al. Residues and distribution character of organochlorine pesticides in soils in Nanjing area (in Chinese). Acta Scientiae Circumstantiae, 2005, 25(4): 470-474

24 Geng C Z, Li M L, Yang Y L, et al. Study and analysis of pollution level of OCPs and PCBs in soils in Qingdao area (in Chinese). J Qingdao University (E \& T), 2006, 21(2): 42-48 $\mathrm{HCH}$ in soils of Tianjin area (in Chinese). China Environ Sc, 2003, 23(3): $311-314$

26 Zhang T B, Rao Y, Wan H F, et al. Content and compositions of organochlorinated pesticides in soil of Dongguan city (in Chinese). China Environ Sci, 2005, 25(S1): 89-93

27 Cheng H R, Zhang G, Jiang J X, et al. Organochlorine pesticides, polybrominated biphenyl ethers and lead isotopes during the spring time at the Waliguan Baseline Observatory, northwest China: implication for long-range atmospheric transport. Atmos Environ, 2007, 41(22): $4734-4747$

28 Halsall C J, Bailey R, Stern G A, et al. Multi-year observations of organohalogen pesticides in the Arctic atmosphere. Environ Pollut,
1998, 102(1): $51-62$

29 Lammel G, Ghim Y S, Grados A, et al. Levels of persistent organic pollutants in air in China and over the Yellow Sea. Atmos Environ, 2007, 41(3): 452-464

30 Li J, Zhu T, Wang F, et al. Observation of organochlorine pesticides in the air of the Mt. Everest region. Ecotoxicol and Environ Safety, 2006, 63(1): $33-41$

31 Qiu X H, Zhu T, Jing L, et al. Organochlorine pesticides in the air around the Taihu Lake, China. Environ Sci Technol, 2004, 38(5): $1368-1374$

32 Sun P, Backus S, Blanchard P, et al. Temporal and spatial trends of organochlorine pesticides in Great Lakes precipitation. Environ Sci Technol, 2006, 40(7): 2135-2141

33 Liu W J, Chen D Z, Liu X D, et al. Application of passive air sampling in monitoring of organochlorine pollutants in atmosphere (in Chinese). Res Environ Sci, 2007, 20(4): 9-14

34 Willett K L, Ulrich E M, Hites R A. Differential toxicity and environmental fates of hexachlorocyclohexane isomers. Environ Sci Technol, 1998, 32(15): 2197-2207

35 Qiu X H, Zhu T, Yao B, et al. Contribution of dicofol to the current DDT pollution in China. Environ Sci Technol, 2005, 39(12): $4385-4390$

\section{Science in China Series B: Chemistry}

\section{EDITOR-IN-CHIEF}

LI Lemin

College of Chemistry and Molecular Engineering

Peking University

Beijing 100871, China

\section{AIMS AND SCOPE}

Science in China Series B: Chemistry, an academic journal cosponsored by the Chinese Academy of Sciences and the National Natural Science Foundation of China, and published by Science in China Press and Springer, is committed to publishing high-quality, original results in both basic and applied research.

Science in China Series B: Chemistry is published monthly in both print and electronic forms. It is indexed by Science Citation Index.

\section{SUBMISSION: www.scichina.com}

\section{Orders and inquiries:}

\section{China}

Science in China Press; 16 Donghuangchenggen North Street, Beijing 100717, China; Tel: +86 1064034559 or +86 1064034134 ;

Fax: +86 1064016350

\section{North and South America}

Springer New York, Inc.; Journal Fulfillment, P.O. Box 2485; Secaucus, NJ 07096 USA; Tel: 1-800-SPRINGER or 1-201-348-4033;

Fax: 1-201-348-4505; Email: journals-ny@springer-sbm.com

Outside North and South America

Springer Distribution Center; Customer Service Journals; Haberstr. 7, 69126 Heidelberg, Germany; Tel: +49-6221-345-0,

Fax: +49-6221-345-4229; Email: SDC-journals@springer-sbm.com 